\title{
Movement-related potentials in the Go/NoGo task: The P3 reflects both cognitive and motor inhibition
}

\author{
Janette L. Smith ${ }^{1,2}$, Stuart J. Johnstone ${ }^{2}$ and Robert J. Barry ${ }^{2}$
}

1. School of Psychology, University of Newcastle, University Drive, Callaghan, NSW 2308, Australia

2. School of Psychology and Brain \& Behaviour Research Institute, University of Wollongong, Northfields Avenue, Wollongong NSW 2522, Australia

****Note to type-setter: "Brain \& Behaviour Research Institute" is a registered name and should not be changed in any way.****

Corresponding author: J. L. Smith. Tel.: (+612) 4921 7096; Fax: (+612) 4921 6980; Email address: janette.smith@newcastle.edu.au 


\section{ABSTRACT}

Objective: The contribution of movement-related potentials (MRPs) to the Go/NoGo N2 and P3 'inhibitory' effects is controversial. This study examined these components in overt and covert response inhibition tasks.

Methods: Twenty adult participants counted or button-pressed in response to frequent $(60 \%)$ and rare $(20 \%)$ Go stimuli in a Go/NoGo task with equiprobable rare $(20 \%)$ NoGo stimuli.

Results: The N2 NoGo effect did not differ between Count and Press responses, but the P3 NoGo effect was amplified during the Press task. Additionally, subtraction of the ERP waveform for Count NoGo from Press NoGo trials revealed a positivity between 200 and $400 \mathrm{~ms}$, occurring maximally over the central region, contralateral to the responding hand. This difference wave became significant at $210-260 \mathrm{~ms}$, close to the estimated time taken to stop an overt response.

Conclusions: The N2 NoGo effect may reflect a non-motoric stage of inhibition, or recognition of the need for inhibition, while the NoGo P3 may overlap with a positive MRP occurring specifically on trials where overt motor responses must be inhibited.

Significance: The study confirms that the N2 and P3 NoGo effects are not solely due to movement-related potentials, and posits the NoGo P3 as a marker of motor inhibition.

Keywords: inhibition; movement-related potentials; N2; P3; NoGo 


\section{Introduction}

In the Go/NoGo task, it is common to observe a larger frontal N2 and frontocentral P3 on trials where inhibition is needed (e.g., Kok, 1986; Jodo and Inoue, 1990; Jodo and Kayama, 1992; Bokura et al., 2001; van Boxtel et al., 2001; Bekker et al., 2004; Smith et al., 2006). Results from the stop-signal task are more complex: the N2 is larger, and the P3 smaller when inhibition fails (De Jong et al., 1990; Dimoska et al., 2003; Kok et al., 2004; Ramautar et al., 2004; Dimoska et al., 2006; but see Schmajuk et al., 2006 for a larger N2 for successful stops). The functional significance of these effects is under debate: apart from the possibility of attentional differences, the N2 may represent motor inhibition (e.g., Kok, 1986; van Boxtel et al., 2001) or detection of response conflict (Nieuwenhuis et al., 2003; Donkers and van Boxtel, 2004), while recently, other researchers have argued that the P3 represents the inhibitory process (Kok et al., 2004; Ramautar et al., 2004; Bekker et al., 2005; Dimoska et al., 2006; Smith et al., 2006, 2007).

In most of the Go/NoGo literature, the contribution of movement-related potentials to the NoGo N2 and P3 effects has been controversial. For example, it is possible that, rather than increased positivity in the P3 range reflecting increased inhibitory activity on NoGo and successful inhibition trials, the effects result from movement-related negativity occurring on Go and failed inhibition trials. The literature seems to have readily adopted the position that variations in N2 and P3 represent at least some real inhibitory activation differences, yet the majority of researchers cite only two studies (Pfefferbaum et al., 1985; Bruin and Wijers, 2002) which have examined overt/motor forms of inhibition (e.g., "button press to Go but not NoGo stimuli") along with covert/non-motor inhibition (e.g., "count the Go but not NoGo stimuli"), seemingly ignoring recent evidence which suggests that motor potential overlap may 
contribute to some of these effects. Because of the importance of these findings for theories of inhibitory control, it is essential to determine whether the N2 and P3 'inhibitory' components differ when overt vs. covert responses are inhibited.

Pfefferbaum et al. (1985) examined the effects on N2 and P3 in an equiprobable visual Go/NoGo task. In separate blocks, participants either counted or button-pressed to Go stimuli. The NoGo N2 effect was present during both tasks, but larger in the press condition. For the P3, a frontocentral increase for NoGo stimuli was observed in both the count and press blocks, with no significant main effect of task. The authors concluded that the NoGo effects were not dependent on the execution or inhibition of an overt motor response.

Bruin and Wijers (2002) had participants perform a visual Go/NoGo task with varying levels of Go stimulus probability $(25 \%, 50 \%$ and $75 \%)$, with counting or button pressing in response to the Go stimuli. The usual N2 NoGo effect, and frontocentral increase in $\mathrm{P} 3$ to NoGo stimuli, were reported for the press condition. In the count condition, a similar N2 effect was found, although the P3 effects differed from the press version: the NoGo P3 in the count condition was never larger in amplitude than the Go P3, even at frontocentral sites. This last result is not mentioned in the majority of the current literature, and Bruin and Wijers did not discuss it.

For support on its position on inhibitory vs. movement-related potential explanations of the N2 and P3 NoGo effects, the literature usually cites only the above two studies, yet recent evidence both supports and contradicts those results. In other studies, the N2 NoGo effect has been established as identical (or at least not significantly different) for overt and covert responses (Bruin and Wijers, 2002; Wang et al., 2002; Burle et al., 2004), in contrast to Pfefferbaum et al.'s (1985) original result, and van 't Ent and Apkarian (1999) have found similar N2 and P3 NoGo effects when the participants responded with a button press and with a saccadic eye movement. The effect of response 
mode on P3 is more controversial still: similar to Pfefferbaum et al. (1985), Starr et al. (1995) found no main effect of task, while Polich (1987) and Barrett et al. (1987) report larger P3 amplitudes with covert than overt responses, and Burle et al. (2004) reported larger P3 amplitudes for an actual rather than imagined response. Hatta et al. (1997) have further reported that P3 amplitude to non-targets was not affected by task, while topography to targets was. In addition, the Go/NoGo effects on P3 are also under debate: Burle et al. (2004) supported Pfefferbaum et al. (1985) by describing similar NoGo P3 effects in overt and covert tasks, yet Nakata et al. (2004) found similar results to Bruin and Wijers (2002), of no frontocentral increase for NoGo relative to Go in their Count condition. Thus, the issue of true inhibitory vs. movement-related Go/NoGo differences is far from resolved.

The most convincing evidence for the influence of movement potentials, in relation to the P3 in particular, comes from Salisbury's group. Salisbury et al. (2001) had participants perform three tasks: an oddball task in which subjects counted rare $(15 \%)$ auditory targets; an identical task in which subjects pressed to these targets; and a task in which subjects pressed to the same auditory targets on $100 \%$ of trials. The target-locked waveforms in this third task were assumed to be a good model of movement-related activity, but without any overlap with the P3 since participants responded on every trial. Salisbury et al. subtracted ERPs from the simple RT task from ERPs in the oddball task requiring a motor response, after matching RTs from both tasks. The corrected and uncorrected press oddball P3 were then compared to P3 from the count oddball task. Before correction, P3 amplitude to press-targets was smaller in the midline, and showed a parietally maximal topography, as compared to the centroparietal maximum in the count task. The removal of movement-related potentials via the correction procedure increased midline P3 amplitude to the press-targets, mostly in the frontocentral region, but did not change the amplitude or topography of the P3 relative to count-targets in normalised 
data. Laterally, the uncorrected P3 showed a left $<$ right effect in frontal and central regions, while the corrected P3 was symmetrical. The authors stated that the typical frontocentral Go/NoGo effect may be produced by a general reduction in Go P3 due to movement-related potentials at these sites, rather than an amplitude increase on NoGo trials.

Salisbury et al. (2004) presented participants with a series of tones, with three tasks associated with these stimuli. In one task, participants were required to silently count the number of rare $(15 \%)$ stimuli embedded in the series of frequent stimuli ('silent-count task'). In another task, participants were required to respond to the rare stimuli with a button press ('Go task'), and in the third task, participants were required to respond to the frequent but not the rare stimuli ('NoGo task'). ERPs to rare stimuli were compared and revealed that the Go P3 showed the usual frontocentral reduction relative to the NoGo P3, and that the NoGo P3 was almost identical in amplitude and topography to the silent-count P3. The authors suggested, therefore, that the P3 'NoGo' effect was due not to the action of a separate inhibitory mechanism on NoGo trials (since no inhibition occurred on the silent-count trials), but rather to the overlap of movement-related potentials on Go trials.

Although the arguments of Salisbury et al. (2004) are strong, it would be more convincing if their experimental protocol included another condition where participants counted the frequent stimuli in a factorial design (overt vs. covert response and Go vs. NoGo decision), to provide a sample of covert inhibitory processing. Furthermore, a study is needed with rare NoGo stimuli, to ensure responses are prepotent and that inhibition is difficult, but that also controls for the effects of stimulus probability on the Go response. Thus the present study used three separate target stimuli: a rare $(20 \%)$ NoGo, a rare $(20 \%)$ Go, and a different, frequent $(60 \%)$ Go stimulus. Participants counted or pressed in response to both Go stimuli. Comparisons of ERPs to the rare Go 
and NoGo stimuli will elucidate the effects of making or inhibiting a covert vs. overt response, free from the problems associated with differing stimulus probabilities, yet ensuring that inhibition is difficult. If the N2 NoGo effect is apparent in both Count and Press tasks, then it would seem to reflect the inhibition of a planned, prepotent response (or the response conflict associated with an infrequent NoGo 'response', e.g., Band et al., 2003; Donkers \& van Boxtel, 2004). If the N2 effect is apparent only in the Press block, that would tend to suggest motoric inhibition. The P3 is expected to be larger in the Count condition, consistent with most previous research, but if the amplitude or topography of the P3 NoGo effect differs between tasks, this would suggest that the P3 NoGo effect is at least partly due to motor potential overlap.

\section{Methods}

Subjects

Participants were 20 adults (12 female) with a mean age of 22.4 years (SD 5.6 years) who participated to fulfil an undergraduate course requirement. No participants had consumed caffeine in the two hours prior to testing, or alcohol or illicit drugs in the 24 hours prior to testing. In addition, none had any evidence of seizure-related disorders, or vision or hearing problems, or were taking any medication. The research protocol was approved by the joint University of Wollongong and Illawarra Area Health Service Human Research Ethics Committee before data collection began.

\section{Apparatus and stimuli}

All subjects completed four blocks of a cued-Go/NoGo task. In each trial, a $1500 \mathrm{~Hz}$ warning tone ${ }^{1}$ was followed $1500 \mathrm{~ms}$ later by one of three tones: a $750 \mathrm{~Hz}$ tone (presented on $60 \%$ of trials), a $1000 \mathrm{~Hz}$ tone $(20 \%$ of trials) or a $2000 \mathrm{~Hz}$ tone $(20 \%$ of trials). Thus, the Go tones were always lower, and the NoGo tone always higher than the 
warning stimulus. There was then a variable interval $(3.0-4.0 \mathrm{~s}, 3.5 \mathrm{~s}$ mean) until the next warning stimulus. All stimuli were binaurally presented through headphones at $70 \mathrm{~dB}$ SPL for $200 \mathrm{~ms}$ (40 ms rise and fall time), with no two $2000 \mathrm{~Hz}$ trials occurring in succession. Previous research has shown that a significant N2 NoGo effect can be achieved with pitch stimuli in both motor and non-motor tasks (e.g. Kiefer et al., 1998; Burle et al., 2004; Kaiser et al., 2006).

\section{Procedure}

Two tasks were associated with these stimuli: In the Press task, participants were instructed to press a hand-held button with their right index finger as quickly as possible to the $750 \mathrm{~Hz}$ and $1000 \mathrm{~Hz}$ tones (called High Probability Go [HPG] and Low Probability Go [LPG], respectively), and not to the $2000 \mathrm{~Hz}$ tone (the NoGo stimulus). In the Count task, participants were instructed to covertly count the number of HPG and LPG stimuli in each block, but not the NoGo stimulus. Counts were reported at the end of each block. The number of trials in each block varied, to prevent participants expecting the same number of stimuli in each block and thus failing to count in the second block. Participants were made aware of this variation. Each block consisted of at least 75 trials (45 HPG, 15 LPG, 15 NoGo), after which the stimulus computer randomly delivered another 0 to 5 trials, of any stimulus type. Participants' reported counts were matched against a count generated by the stimulus computer. Participants completed 10 practice trials, followed by 2 experimental blocks of at least 75 trials each, for both the Count and Press tasks. Half the participants performed the Count blocks first. Responses to the rare Go and NoGo targets are considered here.

Participants were familiarised with the testing procedure and laboratory before written informed consent was obtained. Once recording electrodes were fitted, subjects were seated in a sound-attenuated, electrically-shielded chamber where testing took place. 
Instructions for the task appeared on a computer screen for the subject to read, and understanding was checked verbally. Subjects were encouraged to keep as still as possible throughout the task and to keep eye movements to a minimum using a central fixation cross on the computer monitor. When switching between blocks it was additionally explained to the participant that they should try to completely switch tasks: for participants who counted first, it was explained that they should no longer count the stimuli in the Press task, and for participants who pressed first, it was stressed that they should be motionless during the Count task. A short break was given between blocks if necessary.

Recording

An electrode cap containing tin electrodes was fitted, with continuous EEG recorded from 17 sites (Fp1, Fp2, F7, F3, Fz, F4, F8, T3, C3, Cz, C4, T4, T5, P3, Pz, P4, and T6) of the International 10-20 system. Cap electrodes were referenced to linked earlobes. Vertical EOG was measured with tin cup electrodes placed $1 \mathrm{~cm}$ above and below the left eye, and horizontal EOG from electrodes $1 \mathrm{~cm}$ lateral to the outer canthi. Impedances for ear and eye electrodes were below $3 \mathrm{k} \Omega$, with scalp electrodes below 5 $\mathrm{k} \Omega$. The subject was grounded by a cap electrode located midway between Fpz and Fz. EEG and EOG signals were amplified 5,000 times with a bandpass down $3 \mathrm{~dB}$ at 0.01 and $100 \mathrm{~Hz}$, via 24 channels of Grass amplifiers, sampled through a Labmaster A/D card at $512 \mathrm{~Hz}$, and displayed and recorded using Neuroscan software.

\section{Data analysis}

The ERP epoch began $100 \mathrm{~ms}$ before and ended $900 \mathrm{~ms}$ after the Go/NoGo stimulus. Epochs were baselined to the pre-stimulus activity, and digitally low-pass filtered down $48 \mathrm{~dB}$ at $15 \mathrm{~Hz}$. Epochs were rejected if amplitude exceeded $\pm 100 \mu \mathrm{V}$ in 
any EOG channel. Because it could not be determined when errors occurred in the Count task, error trials were not rejected in the Press task. Practice trials and extra trials in each block (occurring after the $75^{\text {th }}$ trial) were not analysed, resulting in a mean of 21 24 epochs being accepted for averaging in each condition. Peaks were detected within specified latency ranges at the sites of maximum amplitude across conditions (170-280 ms at Fz for N2; 250-500 ms at Pz for P3), and then amplitude measurements were taken at the same latency at all other sites (Picton et al., 2000). Due to latency jitter, the N2 peak is not clearly defined in the grand averages, but in individual subjects a clear peak could be easily observed.

\section{Statistical analysis}

Analyses were restricted to the sites F3, Fz, F4, C3, Cz, C4, P3, Pz, and P4, in a 3 x 3 (Lateral x Sagittal) matrix. Amplitude measures were subjected to a repeated-measures ANOVA, with Response Mode (Count/Press) x Stimulus Type (LPG/NoGo) x Lateral (Left/Midline/Right) x Sagittal (Frontal/Central/Parietal) as within-subjects factors ${ }^{2}$. The HPG stimulus type was not considered in any analyses since the primary focus was on Go/NoGo effects with rare but equiprobable stimuli. Orthogonal planned contrasts on the Lateral factor compared left with right hemispheric activation (in Tables, 1 vs. r), and the mean of these with the midline ( $\mathrm{m}$ vs. $1 / \mathrm{r}$ ). Orthogonal planned contrasts on the Sagittal factor compared frontal activity with parietal ( $\mathrm{f} v \mathrm{vs}$. p), and the mean of these with central (c vs. f/p). Such contrasts are optimal for deriving information about the topographic distribution of each component. That is, if the $\mathrm{f} v \mathrm{vs}$. $\mathrm{p}$ effect is significant but the $\mathrm{c} v \mathrm{vs} \mathrm{f} / \mathrm{p}$ is not, a strong frontal maximum/minimum or parietal maximum/minimum is indicated. If the c vs. $f / p$ effect is significant but the $f$ vs. $p$ is not, a strong central maximum (or minimum) is indicated. If both $\mathrm{f} v s . \mathrm{p}$ and $\mathrm{c}$ vs. $\mathrm{f} / \mathrm{p}$ effects are significant, a frontocentral or parietocentral topography is indicated. Similarly, a significant 1 vs. $r$ but 
not $\mathrm{m}$ vs. $1 / \mathrm{r}$ effect indicates strong laterality, a significant $\mathrm{m}$ vs. $1 / \mathrm{r}$ but not $1 \mathrm{vs.} r \mathrm{r}$ effect indicates a midline maximum, while the significance of both $1 \mathrm{vs} . \mathrm{r}$ and $\mathrm{m}$ vs. $1 / \mathrm{r}$ indicates a maximum slightly to one side of the midline. As the contrasts were planned and there were no more of them than the degrees of freedom for effect, no Bonferroni-type adjustment to alpha was necessary (Tabachnick and Fidell, 1996). Also, the single degree of freedom contrasts are not affected by violations of symmetry assumptions common in repeated measures analyses, and thus do not require Greenhouse-Geisser-type corrections. It should be noted that analyses are carried out over a substantial number of variables, each of which may be considered to constitute a separate experiment. This increases the frequency of type I errors, but as this is an increase in frequency, rather than probability, it cannot be 'controlled' by adjustment of $\alpha$ levels (Howell, 1997). Where there were interactions of Type or Response Mode with Lateral or Sagittal factors, ERP data were also submitted to vector scaling (McCarthy and Wood, 1985) and only condition $\mathrm{x}$ topography interactions that remained significant after this procedure are reported. Latency measures were analysed using a Response Mode x Stimulus Type ANOVA. All contrasts reported have $(1,19)$ degrees of freedom.

\section{Results}

\section{Behavioural performance}

Counting performance during the task was excellent, with participants missing, on average, less than one stimulus presentation (mean $=0.8, \mathrm{SD}=1.8$ ). Similarly, in the Press task subjects made few omission errors (accuracy for HPG: 99.7\%; LPG: 94.8\%) and few commission errors (accuracy for NoGo: 93.2\%; Warning: 99.6\%). Button-press RT was significantly shorter for HPG than LPG trials (434 vs. 545 ms; F = 37.5, p < $.001)$. 


\section{Go/NoGo ERP analyses}

Grand mean ERPs to NoGo and LPG stimuli can be seen in Figure 1. An early ( $\sim 100 \mathrm{~ms})$ frontocentral negativity can be seen for both stimulus types and tasks, which is followed in the Go ERPs by a P2-N2-P3 complex, which is of relatively small amplitude in the Count task. In contrast, a sustained negativity is seen in the NoGo waveforms, followed by a large P3 component ${ }_{\downarrow}$ Effect summaries for the N2 and P3 components can be seen in Table 1, while Figure 2 presents topographic maps of activity for these components.

N2 general topography: The N2 component showed a frontal maximum (f vs. p effect), with a right-midline focus ( 1 vs. $\mathrm{r}$ and $\mathrm{m}$ vs. $1 / \mathrm{r}$ effects). A midline $<$ hemispheres effect was non-existent frontally but apparent parietally, and strongest centrally (lateral x sagittal interactions).

N2 Response Mode effects: There was no significant effect of Response Mode on the N2 component.

N2 Stimulus Type effects: There was a global increase following NoGo relative to Go stimuli (type main effect). For Go stimuli, a frontal midline $>$ hemispheres effect and a parietal midline $<$ hemispheres effect was observed, while for NoGo stimuli, a midline $>$ hemispheres effect was observed both frontally and parietally (type $\mathrm{x}$ lateral $\mathrm{x}$ sagittal interaction).

N2 Response Mode x Stimulus Type interactions: Importantly, there were no significant interactions between Response Mode and Stimulus Type.

N2 peak latency: Both Response Mode and Stimulus Type had effects on N2 latency: N2 peaked marginally earlier in the Press than Count block (213 vs. 224 ms; F = 4.1, $\mathrm{p}=.056)$, and earlier following NoGo than Go stimuli (191 vs. $245 \mathrm{~ms} ; \mathrm{F}=40.9$, p $<.001)$. 
P3 General topography: The P3 showed a parietocentral maximum (f vs. $\mathrm{p}$ and c vs. $\mathrm{f} / \mathrm{p}$ effects), with a midline focus (m vs. $1 / \mathrm{r}$ ). The midline $>$ hemispheres effect was smaller frontally than parietally, and strongest centrally (lateral x sagittal interactions).

P3 Response Mode effects: The P3 was globally larger in the Press than Count task (response mode main effect). A left $>$ right effect was larger centrally than frontally/parietally in the Count task, while the reverse was true in the Press task (response mode $\mathrm{x}$ lateral $\mathrm{x}$ sagittal interaction).

P3 Stimulus Type effects: P3 was larger globally to NoGo than Go stimuli (type

\section{Deleted:} main effect).

P3 Response Mode by Stimulus Type interactions: The increase for NoGo stimuli was weaker in the Count than Press task (response mode $\mathrm{x}$ type interaction). In the Count task, the NoGo $>$ Go effect was smaller in the frontal than parietal region, while in the Press task, the effect was larger in the frontal than parietal region (response mode $\mathrm{x}$ type $\mathrm{x}$ sagittal interaction). In the Count task there was a larger left $>$ right effect following Go than NoGo stimuli, but in the Press task, this was true only after NoGo stimuli, with a reversed and reduced effect for Go stimuli (response mode x type x lateral interaction). The increase in the central $>$ frontal/parietal midline $>$ hemispheres effect for NoGo relative to Go stimuli was larger in the Press than Count block, due mainly to an increased NoGo P3 at $\mathrm{Cz}$ in the Press task (response mode $\mathrm{x}$ type $\mathrm{x}$ lateral $\mathrm{x}$ sagittal interaction).

P3 peak latency: Both Response Mode and Stimulus Type had effects on P3 latency: P3 peaked earlier in the Press than Count block (349 vs. 380 ms; F = 8.2, p < $.05)$, and for NoGo than Go stimuli (347 vs. 383 ms; F = 5.1, p $<.05)$.

In summary, the NoGo N2 effect was not significantly different between Count and Press tasks, while the NoGo P3 effect (frontocentral midline increase) was significantly enhanced for Press vs. Count tasks. 
If the data of Salisbury and colleagues (2004) were replicated, then the Count and Press Go ERPs and topographic maps would look very different (as movement-related potentials decrease the Go P3 amplitude in the Press but not Count block), while the NoGo amplitudes would be quite similar. Inspection of the ERPs in Figure 1 and the topographic maps in Figure 2 reveals that this is not the case. Rather, the figures suggest that the Go response is quite similar between tasks (with increased amplitudes for the Press block), while the NoGo P3 is very different. Subtraction of the Count from the Press waveforms for Go and NoGo trials separately results in the difference waveforms seen in Figure 3. There is a small difference of about $3 \mu \mathrm{V}$ in the P3 range for Go stimuli, and a much greater difference following NoGo stimuli (approximately 200-400 ms poststimulus). It is important to note that for NoGo trials, the same stimulus was presented, and no overt response was made in either block, yet the inbibition of an overt response occurs in the Press but not Count block. The timing and topography of the maximal difference might thus be informative about this motor inhibition process. As with previous analyses, a measurement of peak amplitude in the latency range 200-400 ms for the NoGo difference wave was made at $\mathrm{C} z$, and then an amplitude measure was taken at all other sites at the same latency. We correlated RT on the sample of HPG trials with these amplitude measures, separately for each electrode site, and found that these measures were associated at all sites beyond $r=-.400$ ( $\mathrm{p} \leq .080$ ), with shorter RT reflected in a greater Press $>$ Count NoGo difference.

Analyses compared the topography of the NoGo P3 difference between tasks in the usual Lateral x Sagittal design. Note that no analysis of the NoGo N2 difference between tasks was undertaken, since the main analyses showed no Response Mode $\mathrm{x}$ Stimulus Type interaction. The Press-Count NoGo difference peaked at a mean of 301 $\mathrm{ms}(\mathrm{SD}=52 \mathrm{~ms})$, and was greater centrally than frontally/parietally (see Table 2$)$. The 
effect was larger in the left than right hemisphere, and greater still in the midline, with a vertex maximum.

In addition, the onset/offset of the wave was determined by a range of point-bypoint t-tests, which determined the times in which the difference waveform was significantly different from zero. Because the large number of t-tests would greatly increase the number of false positives, onset was defined by 20 or more consecutive significant results. Onset of significance ranged between different sites from 217 to 264 ms, and, with a similar definition, offsets ranged from 363 to 394 ms.

In summary, the N2 NoGo effect was not significantly different between motor and non-motor versions of the Go/NoGo task, while the P3 NoGo effect (the frontocentral midline increase for NoGo relative to Go stimuli) was significantly enhanced for the Press vs. Count task. Examination of Press - Count difference waves revealed greater similarity between Go than NoGo waveforms, and an increased P3 was observed over the contralateral motor cortex on trials where an overt compared to covert response was inhibited.

\section{Discussion}

The study was designed to assess the effect of executing and withholding an overt or covert response, while controlling for stimulus probability. Participants counted or pressed in response to both low and high probability Go stimuli, while withholding that (overt or covert) response to low probability NoGo stimuli. The N2 NoGo effect was not statistically different between the Press and Count tasks, while the P3 NoGo effect was markedly increased for motor compared to non-motor inhibition.

The Count and Press tasks are undoubtedly experienced very differently by the participants, with different processes occurring. For example, in the Press block the participants' task for each trial is finished with the execution or inhibition of a motor 
response, while in the Count block, the task of keeping a running tally does not finish until the end of the block. Burle et al. (2004) have found similar N2 and P3 effects in overt and covert inhibition tasks, using trials where participants imagine making the Go response. This strategy undoubtedly induces response processes more similar to the Press task, yet it provides no behavioural check that subjects were performing any task at all. We consider that, despite the non-motor processes in the Count task, it nevertheless requires inhibitory control for successful performance.

The relative frequency (and therefore prepotency) of Go responses is often argued to elicit inhibitory processes to rare NoGo stimuli. Additionally, although it is possible that participants used different strategies to those instructed in the Count task, it is unlikely that this is the case. For example, rather than inhibiting a tendency to add one when NoGo stimuli were presented in the Count task, subjects could simply have added zero, or added and then subtracted one. However, it is doubtful that subjects would perform this extra cognitive work on every trial (although certainly the latter strategy is likely on individual trials, since the Count task affords the possibility of covert correction of errors, while the Press task does not).

Another potential difference between tasks is the time pressure involved. Participants were instructed to press the button quickly and accurately in the Press task, but the time pressure was reduced in the Count task (note that this criticism applies equally to Imagine trials, since the experimenter cannot know that the participants imagine their response with a similar RT). In the Count task, subjects could wait until the next Go trial and add two. However, again it is unlikely that participants would choose to perform the extra cognitive work involved with this strategy. Therefore, we believe that the high frequency of the Go stimuli would elicit a tendency to add one when NoGo stimuli were presented, and inhibition was required to successfully overcome this bias. 
The N2 NoGo > Go effect was significant globally, once again confirming that such an effect can be recorded with auditory stimuli (Karlin et al., 1970; Schröger, 1993; Falkenstein et al., 1995; Kiefer et al., 1998; Falkenstein et al., 1999; Falkenstein et al., 2002; Nieuwenhuis et al., 2004; Kaiser et al., 2006; Smith et al., 2006, 2007). In addition, the effect cannot be due to differences in stimulus probability, as could be argued for many Go/NoGo tasks, since LPG and NoGo stimuli had the same low frequency $(20 \%)$. The topographic maps show the NoGo N2 is somewhat lateralised over the right frontal region, consistent with previous reports on this area's association with inhibitory processes (e.g., Casey et al., 1997; Rubia et al., 2001, 2003; Smith et al., 2004). It appears, therefore, that the $\mathrm{N} 2$ component measured here has much in common with previous reports on the $\mathrm{N} 2$.

Importantly, there was no interaction between Response Mode and Stimulus Type, indicating that the N2 NoGo effect is independent of the type of response required. This is in contrast to the original study by Pfefferbaum et al. (1985), who reported that while the $\mathrm{N} 2 \mathrm{NoG}$ effect was apparent in the Count task, it was larger for the Press task. The current results concur with Bruin and Wijers (2002), Wang et al. (2002) and Burle et al. (2004) in finding no significant difference in the N2 NoGo effect for overt and covert responses. These results suggest that the N2 NoGo effect does not reflect motor inhibition, but may instead reflect cognitive processes such as the participants' recognition of the need for inhibition (e.g., Kok's (1986) 'red flag' hypothesis). Alternately, the increased N2 could signal conflict between the intended Go response and the required NoGo response (see, for example, Nieuwenhuis et al., 2003; Band et al., 2003; Donkers \& van Boxtel, 2004). However, distinguishing between these potential explanations is not possible with the current data.

The P3 NoGo effect was apparent in both versions of the task, but was reduced in magnitude in the Count task. Previous researchers have argued that the anterior shift 
of the NoGo P3 in motor tasks is due to the overlap of movement-related potentials, with the effect caused by increased negativity on Go trials at frontal and central sites (Salisbury et al., 2001, 2004). If this were true, one would expect NoGo P3 to be quite similar in the Count and Press tasks, and the Go P3 to differ substantially between response modes (with a smaller P3 frontocentrally for the Press than Count task, and/or the Count Go to be similar to the Press NoGo, as argued by Salisbury et al., 2004). This was not the case, however. When comparing the Count and Press tasks, very similar Go/NoGo effects were seen (although the P3 NoGo effect was larger in the Press block, particularly at $\mathrm{Cz}$ ). This suggests that inhibition was required in both blocks, but more so when motoric inhibition was necessary. The ERPs in Figure 1 and topographic maps in Figure 2 suggest that the Go response is quite similar between Count and Press tasks, and it is the NoGo response that differs greatly between tasks. Furthermore, the NoGo P3 increase for Press relative to Count trials was localised in the central region, and somewhat to the left of midline, contralateral to the responding hand (Figure 3 and Table 2). This increased positivity is indicative of some additional process that occurs on Press NoGo but not Count NoGo trials and is increased in subjects with fast responses (for whom inhibition is presumably more difficult), as shown by the correlation analyses. The timing of the component (an onset of significance in the range 217-264 ms) is reminiscent of the established stop-signal reaction time of 200-250 ms (Band et al., 2003; Schmajuk et al., 2006). Given the topography and timing, the positivity may reflect a motoric inhibition process, active only in the Press task.

It thus appears that the argument of some previous researchers, that motor potential overlap is responsible for the P3 NoGo effect, is partly correct. Because the NoGo P3 effect is apparent for both covert and overt response inhibition, it seems that the NoGo P3 does reflect some kind of inhibitory process, but movement-related potentials also contribute to the effect. However, while previous researchers proposed 
that the NoGo P3 effect was due to increased movement-related negativity on Go trials, it rather appears that the effect is due to increased movement-related positivity on NoGo trials in the central region contralateral to the responding hand. This is further evidence to support the interpretation of the P3 NoGo effect being due to real component differences, rather than solely movement-related potential overlap.

The lack of time pressure may be a limitation in this study, and may account for the latency jitter and reduction of P3 for both trial types in the Count task. Indeed, it could be argued that the reduced pressure for a fast response decreases the need for inhibition, thus explaining the reduced NoGo P3 (if it is indeed a measure of inhibition). However, we think it relevant that the NoGo P3 effect was observed in both tasks, and that the topography and timing of the increased P3 for motor inhibition was as observed. Future research could consider Press, Count and Imagine trials in the same set of subjects, with a shorter ISI to increase the time pressure in the covert tasks, and/or remove the instructions to make Press responses quickly. Source localisation methods and the use of both left- and right-handed responses would allow confirmation of the NoGo P3 result as a motor-related effect (as opposed to simply a left-hemisphere advantage). It is difficult to explain the difference between our P3 results (Press $>$ Count across trial types, similar to Burle et al., 2004) and those of previously published studies: there was no main effect for response mode in Pfefferbaum et al. (1985) and Starr et al. (1995), while Polich (1987), Barrett et al. (1987) and Salisbury et al. (2001, 2004) all report a Count > Press effect. The conflict of results may be due to stimulus probabilities: Burle et al. were the only researchers who required participants to respond overtly and covertly during a frequent $\mathrm{Go}_{\mathrm{O}}$ /rare NoGo series, as in this study. The studies reporting a larger P3 with covert than overt responses all required participants to count or press to rare (15\%-20\%) target stimuli. Button pressing in response to rare targets is simpler than keeping a mental count of those infrequently occurring stimuli. However, when the 
response is frequent, and the interval between count updates is shorter, keeping track of the Count may be easier than when the response is infrequent. Indeed, Bruin and Wijers (2002) considered the effects of changing Go and NoGo stimulus probabilities on Count vs. Press responses, but although it appears from the waveforms that increasing Go stimulus probability resulted in a larger Press $>$ Count effect, they did not directly test this. Thus, the relative frequency of the Go response in this study and in Burle et al.'s may account for the larger P3 during the Press task, but the influence of stimulus probability on the Press/Count P3 effects requires further investigation.

In summary, the current study has shown that the N2 NoGo effect is not related to motoric inhibition, but rather may reflect the recognition that no response is necessary, or the conflict arising from that recognition. Since the NoGo P3 effect was apparent in both tasks, at least part of the effect must be due to cognitive or non-motor inhibition. However, comparison of Go/NoGo P3 effects in Press and Count conditions has isolated a positive potential, maximal over central regions contralateral to the responding hand, and active $220-260 \mathrm{~ms}$ after the NoGo stimulus, approximately the known time taken to stop a response. This positivity may reflect a motoric inhibition process, since it was present on Press but not Count NoGo trials. 


\section{Footnotes}

1. This elicited a late $\mathrm{CNV}$ which was predictably larger across the scalp, and showed a stronger midline $>$ hemispheres effect for the Press than Count block. However, we do not believe that $\mathrm{CNV}$ resolution differences are responsible for the P3 effects observed here. We view the subtraction of the CNV from NoGo but not Go P3 (e.g. Roberts et al, 1994 and Verleger et al., 2006, following Simson et al.'s 1977 approach) as a poor method in any but Simson et al's delayed response experiment, where CNV resolution could reasonably be argued to affect only the NoGo response. Furthermore, a similar NoGo effect is seen when no foreperiod and variable ISIs are used (i.e., when the CNV is less likely to develop (e.g. Bruin and Wijers, 2002; Kiefer et al., 1998; but especially Donchin et al., 1975). Additionally, Oddy et al. (2005) have shown by use of principal components analysis that CNV resolution is not substantially different for Go and NoGo trials in the P3 range, and that the removal of the CNV leaves intact the usual N2 and P3 NoGo effects (both referenced to a pre-S2 baseline). Thus, we believe the current results are not due to differences in $\mathrm{CNV}$ resolution between Go and NoGo trials in the Press and Count tasks.

2. Because the effects of responding/counting vs. not responding/not counting might conceivably differ depending on which was performed first, the above analyses were initially run with the additional between-subjects factor Order (Press first/Count first). Since the main focus of the study was the effect of Response Mode (R) on inhibitory/Stimulus Type $(\mathrm{T})$ differences, reflected in $\mathrm{R} \times \mathrm{T}$ interactions, and no $\mathrm{R} \times \mathrm{T}$ interaction with Order reached significance, the Order factor was not included in the analyses reported below.

Acknowledgements: The authors thank Rodney Davies for assistance with stimulus presentation programming. 


\section{References}

Band GPH, Ridderinkhof KR, van der Molen MW. Speed-accuracy modulation in case of conflict: the roles of activation and inhibition. Psychol Res 2003;67:266-279.

Barrett G, Neshige R, Shibasaki H. Human auditory and somatosensory eventrelated potentials: effects of response condition and age. Electroenceph Clin Neurophysiol 1987;66:409-419.

Bekker EM, Kenemans JL, Koeksma MR, Talsma D, Verbaten MN. The pure electrophysiology of stopping. Int J Psychophysiol 2005;55:191-198.

Bekker EM, Kenemans JL, Verbaten MN. Electrophysiological correlates of attention, inhibition, sensitivity and bias in a continuous performance task. Clin Neurophysiol 2004;115:2001-2013.

Bokura K, Yamaguchi S, Kobayashi S. Electrophysiological correlates for response inhibition in a Go/NoGo task. Clin Neurophysiol 2001;112:2224-2232.

Bruin KJ, Wijers AA. Inhibition, response mode, and stimulus probability: a comparative event-related potential study. Clin Neurophysiol 2002;113:1172-1182.

Burle B, Vidal F, Bonnet M. Electroencephalographic nogo potentials in a nomovement context: the case of motor imagery in humans. Neurosci Let 2004;360:77-80.

Casey BJ, Castellanos FX, Giedd JN, Marsh WL, Hamburger SD, Schubert AB, Vauss YC, Vaituzis AC, Dickstein DP, Sarfatti SE, Rapoport JL. Implication of right frontostriatal circuitry in response inhibition and attention-deficit/hyperactivity disorder. J Amer Acad Child Adolesc Psychiatry 1997;36:374-383.

De Jong R, Coles MGH, Logan GD, Gratton G. In search of the point of no return: the control of response processes. J Exp Psychol Hum Percept Perform 1990;16:164-182. 
Dimoska A, Johnstone SJ, Barry RJ. The auditory-evoked N2 and P3 components in the stop-signal task: Indices of inhibition, response-conflict or errordetection? Brain Cogn 2006;62:98-112.

Dimoska A, Johnstone SJ, Barry RJ, Clarke AR. Inhibitory motor control in children with Attention-deficit/Hyperactivity Disorder: Event-related potentials in the stop-signal paradigm. Biol Psychiat 2003;54:1340-1349.

Donchin E, Tueting P, Ritter W, Kutas M, Heffley EF. On the independence of the CNV and the P300 components of the human averaged evoked potential. Electroenceph Clin Neurophysiol 1975;38:449-461.

Donkers FCL, Van Boxtel GJM. The N2 in go/no-go tasks reflects conflict monitoring not response inhibition. Brain Cogn 2004;56:165-176.

Falkenstein M, Hoormann J, Hohnsbein J. ERP components in Go/Nogo tasks and their relation to inhibition. Acta Psychol 1999;101:267-291.

Falkenstein M, Hoormann J, Hohnsbein J. Inhibition-related ERP components: variation with modality, age, and time-on-task. J Psychophysiol 2002;16:167-175.

Falkenstein M, Koshlykova NA, Kiroj VN, Hoormann J, Hohnsbein J. Late ERP components in visual and auditory Go/Nogo tasks. Electroenceph Clin Neurophysiol: Evoked Potentials 1995;96:36-43.

Hatta A, Nishihira Y, Shimoda M, Fumoto M, Ikeda H, Takemiya T. The change of event-related potentials with choice task. Japan J Phys Fit Sports Med 1997;46:405414.

Howell DC. Statistical methods for psychology. Belmont, CA: Wadsworth, 1997.

Jodo E, Inoue K. Effects of practice on the P300 in a Go/NoGo task. Electroenceph Clin Neurophysiol 1990;76:249-257.

Jodo E, Kayama Y. Relation of a negative ERP component to response inhibition in a Go/No-go task. Electroenceph Clin Neurophysiol 1992;82:477-482. 
Kaiser S, Weiss O, Hill H, Markela-Lerenc J, Kiefer M, Weisbrod M. N2 eventrelated potential correlates of response inhibition in an auditory Go/Nogo task. Int J Psychophysiol 2006;61:279-282.

Karlin L, Martz MJ, Mordkoff AM. Motor performance and sensory-evoked potentials. Electroenceph Clin Neurophysiol 1970;28:307-313.

Kiefer M, Marzinzik F, Weisbrod M, Scherg M, Spitzer M. The time course of brain activations during response inhibition: evidence from event-related potentials in a go/nogo task. Neuroreport 1998;9:765-770.

Kok A. Effects of degradation of visual stimuli on components of the eventrelated potential (ERP) in go/nogo reaction tasks. Biol Psychol 1986;23:21-38.

Kok A, Ramautar JR, De Ruiters MB, Band GPH, Ridderinkhof KR. ERP components associated with successful and unsuccessful stopping in a stop-signal task. Psychophysiology 2004;41:9-20.

McCarthy G, Wood CC. Scalp distributions of event-related potentials: An ambiguity associated with analysis of variance models. Electroenceph Clin Neurophysiol 1985;62:203-208.

Nakata H, Inui K, Nishihira Y, Hatta A, Sakamoto M, Kida T, Wasaka T, Kakigi R. Effects of a go/nogo task on event-related potentials following somatosensory stimulation. Clin Neurophysiol 2004;115:361-368.

Nieuwenhuis S, Yeung N, Cohen JD. Stimulus modality, perceptual overlap, and the go/no-go N2. Psychophysiology 2004;41:157-160.

Nieuwenhuis S, Yeung $\mathrm{N}$, van den Wildenberg W, Ridderinkhof KR. Electrophysiological correlates of anterior cingulate function in a go/no-go task: Effects of response conflict and trial type frequency. Cogn Affect Behav Neurosci 2003;3:17-26.

Oddy BW, Barry RJ, Johnstone SJ, Clarke AR. Removal of CNV effects from the N2 and P3 ERP components in a visual Go/NoGo task. J Psychophysiol 2005;19: 24-34. 
Pfefferbaum A, Ford JM, Weller BJ, Kopell BS. ERPs to response production and inhibition. Electroenceph Clin Neurophysiol 1985;60:423-434.

Picton TW, Bentin S, Berg P, Donchin E, Hillyard SA, Johnson R, Miller GA, Ritter W, Ruchkin DS, Rugg MD, Taylor MJ. Guidelines for using human event-related potentials to study cognition: Recording standards and publication criteria. Psychophysiology 2000;37:127-152.

Polich J. Response mode and P300 from auditory stimuli. Biol Psychol $1987 ; 25: 61-71$.

Ramautar JR, Kok A, Ridderinkhof KR. Effects of stop-signal probability in the stop-signal paradigm: The N2/P3 complex further validated. Brain Cogn 2004;56:234252.

Roberts LE, Rau H, Lutzenberger W, Birbaumer N. Mapping P300 waves onto inhibition: Go/No-Go discrimination. Electroenceph Clin Neurophysiol 1994;92:44-55.

Rubia K, Russell T, Overmeyer S, Brammer, M J, Bullmore ET, Sharma T, Simmons A, Williams SCR, Giampietro V, Andrew C, Taylor E. Mapping motor inhibition: Conjunctive brain activations across different versions of Go/No-Go and Stop tasks. Neuroimage 2001;13:250-261.

Rubia K, Smith AB, Brammer MJ, Taylor E. Right inferior prefrontal cortex mediates response inhibition while mesial prefrontal cortex is responsible for error detection. Neuroimage 2003;20:351-358.

Salisbury DF, Griggs CB, Shenton ME, McCarley RW. The NoGo P300 'anteriorization' effect and response inhibition. Clin Neurophysiol 2004;115:1550-1558.

Salisbury DF, Rutherford B, Shenton ME, McCarley RW. Button-pressing affects P300 amplitude and scalp topography. Clin Neurophysiol 2001;112:1676-1684. 
Schmajuk M, Liotti M, Busse L, Woldorff MG. Electrophysiological activity underlying inhibitory control processes in normal adults. Neuropsychologia 2006;44:384395.

Schröger E. Event-related potentials to auditory stimuli following transient shifts of spatial attention in a Go/Nogo task. Biol Psychol 1993;36:183-207.

Simson R, Vaughan HG, Ritter W. The scalp topography of potentials in auditory and visual go/nogo tasks. Electroenceph Clin Neurophysiol 1977;43:864-875.

Smith JL, Johnstone SJ, Barry RJ. Inhibitory processing during the Go/NoGo task: An ERP analysis of children with attention-deficit/hyperactivity disorder. Clin Neurophysiol 2004;115:1320-1331.

Smith JL, Johnstone SJ, Barry RJ. Effects of pre-stimulus processing on subsequent events in a warned Go/NoGo paradigm: Response preparation, execution and inhibition. Int J Psychophysiol 2006;61:121-133.

Smith JL, Johnstone SJ, Barry RJ. Response priming in the Go/NoGo task: The N2 reflects neither inhibition nor conflict. Clin Neurophysiol 2007;118:343-355.

Starr A, Sandroni P, Michalewski HJ. Readiness to respond in a target detection task: pre- and post-stimulus event-related potentials in normal subjects. Electroenceph Clin Neurophysiol 1995;96:76-92.

Tabachnick BG, Fidell LS. Using multivariate statistics. New York: HarperCollins, 1996.

van Boxtel GJM, van der Molen MW, Jennings JR, Brunia CHM. A psychophysiological analysis of inhibitory motor control in the stop-signal paradigm. Biol Psychol 2001;58:229-262.

Van 't Ent D, Apkarian P. Motoric response inhibition in finger movement and saccadic eye movement: a comparative study. Clin Neurophysiol 1999;110:1058-1072. 
Verleger R, Paehge T, Kolev V, Yordanova J, Jaskowski P. On the relation of movement-related potentials to the go/no-go effect on P3. Biol Psychol 2006;73:298313.

Wang Y, Tian S, Wang H, Cui L, Zhang Y. Event-related potentials in a no-go task involving response-tendency conflict. Clin Electroenceph 2002;33:82-85. 


\section{Figure Legends}

Figure 1. Grand mean ERPs to NoGo (heavy) and LPG (light) stimuli in the Count (dashed) and Press tasks (solid). Vertical bars represent stimulus onset. Amplitude in $\mu \mathrm{V}$ and time in ms marked at $\mathrm{Cz}$.

Figure 2. Isopotential maps of N2 and P3 activity following Go and NoGo stimuli in the Press and Count tasks. Spacing between isopotential lines is $1 \mu \mathrm{V}$ for $\mathrm{N} 2$; for the P3 the spacing is $2 \mu \mathrm{V}$. Shaded areas are negative relative to the pre-stimulus baseline.

Figure 3. Grand mean difference waveforms (Press - Count) for NoGo (heavy) and Go (light) stimuli. Vertical bars represent stimulus onset. Amplitude in $\mu \mathrm{V}$ and time in $\mathrm{ms}$ marked at $\mathrm{Cz}$. 


\section{Tables and Figures}

Table 1. Significant results for the N2 and P3 components.

\begin{tabular}{|c|c|c|c|c|c|c|}
\hline \multirow{10}{*}{$\begin{array}{l}\text { Comp. } \\
\text { N2 }\end{array}$} & Effect & Contrast & \multicolumn{2}{|l|}{ Details } & $\mathrm{F}$ & $p$ \\
\hline & $\mathrm{S}$ & f vs. p & \multicolumn{2}{|c|}{-4.8 vs. 0.4} & 86.3 & .001 \\
\hline & $\mathrm{L}$ & l vs. $r$ & \multicolumn{2}{|c|}{-1.9 vs. -2.5} & 6.0 & .025 \\
\hline & & $\mathrm{m}$ vs. $1 / \mathrm{r}$ & \multicolumn{2}{|c|}{-1.7 vs. -2.2} & 6.6 & .019 \\
\hline & $\mathrm{LxS}$ & fz to $\mathrm{f} 3 / \mathrm{f} 4$ vs. pz to $\mathrm{p} 3 / \mathrm{p} 4$ & \multirow{2}{*}{\multicolumn{2}{|c|}{$\begin{array}{l}-4.8 \text { to }-4.8 \text { vs. } 0.9 \text { to } 0.2 \\
-1.3 \text { to }-2.1 \text { vs. }-2.0 \text { to }-2.3\end{array}$}} & 20.4 & .001 \\
\hline & & $\begin{array}{l}\mathrm{cz} \text { to } \mathrm{c} 3 / \mathrm{c} 4 \text { vs. fz/pz to } \\
\mathrm{f} 3 \mathrm{f} 4 / \mathrm{p} 3 \mathrm{p} 4\end{array}$ & & & 8.4 & .009 \\
\hline & $\mathrm{T}$ & Go vs. NoGo & \multicolumn{2}{|c|}{-1.0 vs. -3.1} & 7.3 & .014 \\
\hline & TxLxS & fz to $\mathrm{f} 3 / \mathrm{f} 4$ vs. pz to $\mathrm{p} 3 / \mathrm{p} 4$ & \multirow{2}{*}{\multicolumn{2}{|c|}{$\begin{array}{l}\text { Go: }-4.0 \text { to }-3.7 \text { vs. } 2.1 \text { to } 1.3 \\
\text { NoGo: }-5.6 \text { to }-5.8 \text { vs. }-0.3 \text { to }-0.8\end{array}$}} & 10.3 & .005 \\
\hline & & & & & & \\
\hline & $\mathrm{RxT}$ & Go vs. NoGo & \multicolumn{2}{|c|}{ Count: -0.8 vs. -2.5} & .518 & .481 \\
\hline \multirow[t]{15}{*}{ P3 } & $\mathrm{S}$ & f vs. p & \multicolumn{2}{|c|}{3.7 vs. 11.5} & 114.4 & .001 \\
\hline & & c vs. $\mathrm{f} / \mathrm{p}$ & \multicolumn{2}{|c|}{9.5 vs. 7.6} & 34.0 & .001 \\
\hline & $\mathrm{L}$ & m vs. $1 / \mathrm{r}$ & \multicolumn{2}{|c|}{9.5 vs. 7.6} & 133.9 & .001 \\
\hline & $\mathrm{LxS}$ & fz to $\mathrm{f} 3 / \mathrm{f} 4$ vs. pz to $\mathrm{p} 3 / \mathrm{p} 4$ & \multirow{2}{*}{\multicolumn{2}{|c|}{$\begin{array}{l}4.0 \text { to } 3.5 \text { vs. } 13.1 \text { to } 10.8 \\
11.5 \text { to } 8.5 \text { vs. } 8.5 \text { to } 7.1\end{array}$}} & 42.8 & .001 \\
\hline & & $\begin{array}{l}\mathrm{cz} \text { to } \mathrm{c} 3 / \mathrm{c} 4 \text { vs. } \mathrm{fz} / \mathrm{pz} \text { to } \\
\mathrm{f} 3 \mathrm{f} 4 / \mathrm{p} 3 \mathrm{p} 4\end{array}$ & & & 40.2 & .001 \\
\hline & $\mathrm{R}$ & Count vs. Press & \multicolumn{2}{|c|}{6.7 vs. 9.8} & 7.6 & .013 \\
\hline & RxLxS & c3 to c 4 vs. $\mathrm{f} 3 / \mathrm{p} 3$ to $\mathrm{f} 4 / \mathrm{p} 4$ & \multicolumn{2}{|c|}{$\begin{array}{l}\text { Count: } 7.2 \text { to } 6.5 \text { vs. } 5.9 \text { to } 5.6 \\
\text { Press: } 10.5 \text { to } 9.9 \text { vs. } 9.0 \text { to } 8.0\end{array}$} & 7.4 & .013 \\
\hline & $\mathrm{T}$ & Go vs. NoGo & \multicolumn{2}{|c|}{5.1 vs. 11.4} & 122.6 & .001 \\
\hline & $\mathrm{RxT}$ & Go vs. NoGo & \multicolumn{2}{|c|}{$\begin{array}{l}\text { Count: } 4.2 \text { vs. } 9.2 \\
\text { Press. } 60 \text { vs } 137\end{array}$} & 4.3 & .053 \\
\hline & $\operatorname{RxTxS}$ & fvs. p & & $\begin{array}{l}\text { Go: } 0.4 \text { vs. } 7.2 \\
\text { NoGo: } 4.3 \text { vs. } 12.9\end{array}$ & 8.7 & .008 \\
\hline & & & \multicolumn{2}{|r|}{$\begin{array}{l}\text { Go: } 1.0 \text { vs. } 10.0 \\
\text { NoGo: } 8.9 \text { vs. } 16.2\end{array}$} & & \\
\hline & RxTxL & 1 vs. $\mathrm{r}$ & Count & $\begin{array}{l}\text { Go: } 4.1 \text { vs. } 3.5 \\
\text { NoGo: } 8.6 \text { vs. } 8.2\end{array}$ & 10.0 & .005 \\
\hline & & & Press & $\begin{array}{l}\text { Go: } 5.5 \text { vs. } 5.7 \\
\text { NoGo: } 13.5 \text { vs. } 11.7\end{array}$ & & \\
\hline & RxTxLxS & $\begin{array}{l}\mathrm{cz} \text { to } \mathrm{c} 3 / \mathrm{c} 4 \text { vs. } \mathrm{fz} / \mathrm{pz} \text { to } \\
\mathrm{f} 3 \mathrm{f} 4 / \mathrm{p} 3 \mathrm{p} 4\end{array}$ & Count & $\begin{array}{l}\text { Go: } 6.0 \text { to } 4.4 \text { vs. } 4.3 \text { to } 3.6 \\
\text { NoGo: } 12.5 \text { to } 9.3 \text { vs. } 9.8 \text { to } \\
8.0\end{array}$ & 11.4 & .003 \\
\hline & & & Press & $\begin{array}{l}\text { Go: } 8.3 \text { to } 6.4 \text { vs. } 6.0 \text { to } 5.2 \\
\text { NoGo: } 19.5 \text { to } 14.0 \text { vs. } 14.0 \\
\text { to } 11.9\end{array}$ & & \\
\hline
\end{tabular}

Note for this and subsequent table: Details column represents mean amplitude in $\mu \mathrm{V}$. R, Response Mode: Count/Press. T, Stimulus Type: Go/NoGo. Lateral (L) abbreviations: 1, mean left hemisphere (F3, C3, P3); $\mathrm{r}$, mean right hemisphere (F4, C4, P4); 1/r, mean of the left and right hemispheres (F3, C3, P3, F4, C4, P4); $\mathrm{m}$, mean of the midline ( $\mathrm{Fz}, \mathrm{Cz}, \mathrm{Pz}$ ). Sagittal (S) abbreviations: $\mathrm{f}$, mean frontal (F3, Fz, F4); p, mean parietal (P3, Pz, P4); c, mean central (C3, Cz, C4); f/p, mean of frontal and parietal (F3, Fz, F4, P3, Pz, P4). Lateral by Sagittal (LxS) interactions: sites (e.g. f3) represent position on scalp (e.g. frontal left hemisphere); f3/p3, mean of frontal and parietal left hemisphere; $\mathrm{f} 4 / \mathrm{p} 4$, mean of frontal and parietal right hemisphere; $\mathrm{fz} / \mathrm{pz}$, mean of frontal and parietal midline; $\mathrm{f} 3 / \mathrm{f} 4$, mean of frontal left and right hemispheres; $\mathrm{p} 3 / \mathrm{p} 4$, mean of parietal left and right hemispheres; $\mathrm{c} 3 / \mathrm{c} 4$, mean of central left and right hemispheres; f3f4/p3p 4 , mean of frontal and parietal left and right hemispheres. 
Table 2. Significant topographic results for the NoGo difference wave (Press-Count).

\begin{tabular}{l|llrl}
\hline Effect & Contrast & Details & F & p \\
\hline $\mathrm{S}$ & c vs. f/p & 8.9 vs. 6.8 & 8.0 & .011 \\
$\mathrm{~L}$ & 1 vs. $\mathrm{r}$ & 7.7 vs. 6.2 & 6.4 & .020 \\
& m vs. $1 / \mathrm{r}$ & 8.2 vs. 6.9 & 18.4 & .001 \\
$\mathrm{LxS}$ & cz to c3/c4 vs. fz/pz to f3f4/p3p4 & 10.8 vs. 8.0 vs. 7.5 to 6.4 & 8.6 & .009 \\
\hline
\end{tabular}

